Molecular Reproduction and Development, Vol. 49, No. 1, 1998, pp. 10-18.

ISSN: (print 1040-452X) (online 1098-2795)

DOI: 10.1002/(SICI)1098-2795(199801)49:1<10::AID-MRD2>3.0.CO;2-R

The definitive version is available http://www3.interscience.wiley.com/

http://www.wiley.com/WileyCDA/WileyTitle/productCd-MRD.html

http://www3.interscience.wiley.com/cgi-bin/fulltext/37696/PDFSTART

(C) 1998 Wiley-Liss, Inc.

\title{
Androgenesis and Homozygous Gynogenesis in Muskellunge (Esox masquinongy): Evaluation Using Flow Cytometry
}

\section{FENG LIN AND KONRAD DABROWSKI}

School of Natural Resources, The Ohio State University.

\begin{abstract}
The purpose of this work was to study the effects of ultraviolet (UV) irradiation on denucleation of eggs and investigate the heat-shock conditions for diploidization for induction of androgenesis in muskellunge, Esox masquinongy. Several egg incubation media, including saline, Ringer's solution, and Ringer's solution supplemented with bovine serum albumin (BSA), were found suitable to maintain the egg fertility as high as in muskellunge ovarian fluid. The optimal doses of UV radiation were $660-1320 \mathrm{~J} / \mathrm{m}^{2}$, at which $100 \%$ haploid larvae were produced at a hatching rate of $22.5 \pm 2.8 \%$. UV irradiation at low doses $\left(165-330 \mathrm{~J} / \mathrm{m}^{2}\right)$ generated abnormal larvae, which were morphologically identical to haploids. Using a flow cytometry method, it was found that cellular DNA content of these larvae was close to that of diploids but significantly lower in value and had a wider distribution (expressed as coefficient of variation) than that of control fish. This suggested that a low dose of UV irradiation might cause gene mutations, alteration of chromosomal conformation and fragmentation, but did not prevent maternal DNA from participating in mitotic division. Interference of maternal DNA residues could be another reason for the poor viability of androgenetic fish. A high dose of UV radiation $\left(1980 \mathrm{~J} / \mathrm{m}^{2}\right)$ caused development of severely deformed embryos, indicating that UV radiation also damaged molecules in the eggs other than the denucleation. Our results suggest that classic color and allozyme markers might not be sufficient to prove a complete androgenesis. In order to optimize time and duration of shock for induced diploidization, we investigated the heat-shock conditions for inhibiting the first mitotic cleavage through induction of homozygous gynogenesis. We found that heat-shock treatment at $31{ }^{\circ} \mathrm{C}$ for 9 min starting at $1.4 \tau_{0}$ (a dimensionless factor describing progress in embryo development) after fertilization produced the highest percentage of diploids at hatching.
\end{abstract}

\section{INTRODUCTION}

Androgenesis and homozygous gynogenesis are of interest because the resulting progeny are completely homozygous and possess only chromosomes from a single parental source. Androgenesis has many potential applications, including rapid establishment of an inbred line and recovery of valuable strains from cryopreserved semen (Arai et al., 1992; Myers et al., 1995; Thorgaard et al., 1990). Gamma- or x-ray irradiation has been used to inactivate the genetic materials of eggs for induction of androgenesis in fish (Arai et al., 1979; May et al., 1988; Parsons and Thorgaard, 1984; Purdom, 1969). Recently, ultraviolet (UV) irradiation was applied successfully for androgenesis in loach, Misgurnus anguillicaudatus (Arai et al., 1992, 1995), common carp, Cyprinus carpio (Bongers et al., 1994, 1995), and tilapia, Oreochromis niloticus (Myers et al., 1995). UV irradiation has several advantages over ionizing radiation and is used widely to inactivate spermatozoa for gynogenesis under the consideration of technical complexity such as appropriate facilities and safety issues. Chromosome fragments usually are generated by ionizing irradiation and might interfere with the embryonic development (Chourrout and Quillet, 1982; Parsons and Thorgaard, 1984). UV irradiation is considered not to result in residual DNA fragments and thus is advantageous over gamma irradiation for 
gynogenesis (Chourrout, 1984). However, DNA fragments, probably of maternal chromosome residues, were found in haploid androgenetic loach after eggs were inactivated by UV irradiation (Arai et al., 1992). The effects of UV irradiation on eggs has not been studied extensively, although no changes in mitochondria DNA were observed (Myers et al., 1995).

Flow cytometry has been proven to be a sensitive technique for detecting DNA damage caused by environmental mutagens, including irradiation and chemicals (Dallas and Evan, 1990; Deaven, 1982). Relative DNA content of individual cells can be measured with this device, and distributions of cells in various stages of cell cycle can be estimated with associated computer programs. Flow cytometry has been applied to detect DNA content of red blood cells in turtles (Bickham et al., 1988) and ducks (George et al., 1991) that inhabited radionuclide-contaminated ponds. Aneuploidy and in creased coefficient of variation (CV) of G0/G1 peak have been found in these animals. Bickham et al. (1988) suggested that the increasing variation of DNA content in blood cells was the result of chromosomal rearrangements, leading to deletions and duplications, caused by clastogenic agents. Flow cytometry also has been used for ploidy identification (Allen, 1983; Benfey et al., 1986; Lin and Dabrowski, 1996a) and estimation of DNA content (Johnson et al., 1987; Tiersch et al., 1989).

One of the setbacks for UV irradiation is its weak penetration ability. In order to achieve complete inactivation of eggs, they need to be rotated during UV irradiation. This requires the eggs to be immersed in a fluid. Ovarian fluid from the same female would be the best medium for this purpose; however, it is not always available from females that produce high-quality eggs. Thus it is important to find an artificial medium that can well maintain egg fertility for a time long enough for UV irradiation.

In order to obtain diploid androgenetic fish, UV irradiated eggs should be fertilized with untreated sperm and then heat shocked to inhibit the first mitotic cleavage for diploidization. The same heat-shock treatment would produce homozyous gynogenetic fish if untreated eggs were fertilized with UV-irradiated sperm. We chose to investigate the heat-shock conditions for inhibiting the first mitotic cleavage using UV-irradiated sperm and untreated eggs because it was easier to irradiate sperm than eggs. Heat-shock temperatures and durations were based on our previous experiences in induction of heterozygous gynogenetic muskellunge (Lin and Dabrowski, 1996a). To overcome the problem of various embryonic development speeds at different water temperatures, the initial time of heat-shock treatment was expressed using a dimension less factor termed $\tau_{0}$, which is "the time interval between the first appearance of furrow of the first and the second (or the second and the third) cleavage division" (Dettlaff and Dettlaff, 1966, cited by Rothbard, 1991).

In this work, we studied the effects of several egg incubation media on egg fertility in order to find a replacement solution for ovarian fluid during UV irradiation. We evaluated UV irradiation as a denucleating agent for induction of androgenesis in muskellunge. Using flow cytometry, the effects of UV irradiation on variation in DNA content and embryonic development were monitored.

\section{MATERIALS AND METHODS Reagents}

Hematall and silver nitrate were obtained from Fisher Scientific (Pittsburgh, PA). Dimethylsulfoxide (DMSO), propidium iodide (PI), ribonuclease A, trypsin inhibitor (TI), and all other chemicals were obtained from Sigma Chemical Company (St. Louis, MO). 


\section{Gametes Collection and Handling}

Mature muskellunge were captured using trap nets in the Clear Fork Reservoir, Ohio. Gametes collected from unanesthetized fish were used for androgenesis experiments. Semen was kept on ice before being used. Eggs were kept in a foam box with the temperature maintained at approximately $12^{\circ} \mathrm{C}$ (Lin and Dabrowski, 1996a).

For the homozygous gynogenesis experiment, gametes were collected from muskellunge maintained in hatchery ponds for several seasons at the Minor E. Clark Fish Hatchery, Morehead, Kentucky. Adult fish were treated with carp pituitary extract 3-4 days prior to the gamete collection. Eggs from four females and semen from five males were transferred to our laboratory at The Ohio State University campus as described above. They were used for fertilization 10-12 hours after collection. Sperm motility was checked (Lin and Dabrowski, 1996b), and only semen with more than 90\% initial motile sperm was used for fertilization. Eggs were fertilized with fresh semen to serve as a control for egg quality. Survival to the eyed stage was obtained by counting and removing white (dead) eggs at 7-9 days after fertilization.

\section{Effects of Incubation Media on the Egg Fertility}

We tested the effects of seven incubation media on egg fertility. These included saline (SAL, $0.9 \% \mathrm{NaCl})$, Ringer's solution (RIN), Ringer's solution plus trypsin inhibitor $(0.5 \mathrm{mg} / \mathrm{ml})$ (RIN + Ti) (Hsu and Goetz, 1993), Ringer's solution plus bovine serum albumin (BSA) (5 $\mathrm{mg} / \mathrm{ml}$ ) (RIN + BSA), carp artificial fluid (CAF) (Bongers et al., 1994), sucrose (SUC, $0.3 \mathrm{M}$ ), and muskellunge ovarian fluid. Pooled eggs from two females, approximately 300 eggs, were incubated with $5 \mathrm{ml}$ of each of the preceding media for $10 \mathrm{~min}$ at $13^{\circ} \mathrm{C}$. The solutions were removed before $40 \mu \mathrm{l}$ fresh semen and water was added to fertilize the eggs. Untreated eggs also were fertilized to serve as control $(\mathrm{CON})$ of egg quality. Eggs were incubated in duplicate as described earlier (Lin and Dabrowski, 1996a), and egg fertility was expressed as the survival to the eyed-stage embryos. The osmolality and chemical composition and ionic and protein concentrations of ovarian fluid were measured as de scribed earlier (Lin et al., 1996).

\section{UV Irradiation of Eggs for Inactivation of Genetic Material in Eggs}

Pooled eggs from two females ( $4 \mathrm{~g})$ were dispersed in a 5-cm-diameter Petri dish to form a single layer of eggs. Ovarian fluid of muskellunge $(3 \mathrm{ml})$ was added to the eggs. These eggs were UV-irradiated with a shortwave (254-nm) mineralight lamp (Model UVG-11, UVP, Inc., San Gabriel, CA) at an intensity of $275 \mu \mathrm{W} / \mathrm{cm}^{2}$ for $0,0.5,1,2,4,8$, and $12 \mathrm{~min}$. The intensity of UV irradiation was measured using a UVX radiometer (UVP, Inc., San Gabriel, CA) with a sensor placed at the same level as the eggs. These are equivalencies to the UV dose of $0,82.5$, $165,330,660,1320$, and $1980 \mathrm{~J} / \mathrm{m}^{2}$, respectively. The eggs were gently rotated by hand shaking the Petri dish during irradiation. The experiment was performed in a temperature-controled chamber at $13^{\circ} \mathrm{C}$. After UV irradiation, the ovarian fluid was removed before $40 \mu \mathrm{l}$ fresh semen and water was added to fertilize the eggs. Eggs were divided into two parts and incubated in PVC jars with a screen bottom. These jars were set up in California-type flow-through hatching trays (Flex-a-lite Consolidated, Tacoma, WA) and maintained in the dark. Water temperature was $12-14^{\circ} \mathrm{C}$ during incubation. Survivals to the eyed stage were obtained by counting the dead eggs and total embryos at 7-9 days after fertilization. The dead eggs were removed after counting. The number of hatched larvae, both normal and abnormal, were recorded for hatching rate. Abnormal embryos and larvae were frozen in a solution containing Hematall (Fisher Scientific, Pittsburgh, PA) and 5\% dimethylsulfoxide (DMSO) for flow cytometry analysis of 
DNA content. The pictures of embryos were taken under a dissecting microscopy with a Kodak T-Max 100 film.

\section{Flow Cytometry Measurement of DNA Content}

Frozen abnormal embryos and larvae from UV-irradiation groups were used for measurement of DNA content by the flow cytometry method. Normal hatched larvae also were analyzed for comparison. The method of sample preparation for flow cytometry was described earlier (Lin and Dabrowski, 1996a). Analyses were performed using a Coulter EPICS Elite flow cytometer (Coulter Electronics, Hialeah, FL) calibrated with fluorescent beads. An argon ion laser was used to provide a $15-\mathrm{mW}, 488-\mathrm{nm}$ excitation beam. We collected data on time, fluorescence, forward scatter, and 90-degree scatter to estimate DNA content and cell size. Electronic gating was applied to eliminate possible particle aggregation. The stability of the fluorescence was monitored during data collection. If fluorescence fluctuation was detected, data collection was restarted. Data from at least 10,000 events were collected into a listmode file from each sample and analyzed with the Standard Elite Workstation Software. Relative DNA content was expressed as the ratio of muskellunge $\mathrm{G}_{1} / \mathrm{G}_{0}$ peak position to that of internal standard. Rainbow trout red blood cells were used as an external standard as well as added to the samples as an internal standard. Blood was collected from an individual rainbow trout that was reared in our laboratory.

\section{Chromosome Preparation and Silver Staining for NOR's}

Embryos at the eyed stage were used for chromosome preparation and silver staining for nucleolar organizer regions (NORs) according to methods described previously (Lin and Dabrowski, 1996a). Slides were stained with 10\% Giemsa for chromosomes. Pictures of chromo somes were taken with a Nikon microphot-FXA at a magnification of $125 \times$ with a Kodak TMax 100 film.

\section{Induction of Homozyous Gynogenesis by Heat Shock}

Pooled semen from four males was used in this experiment. A small batch of eggs was fertilized and periodically observed under a microscope to determine the dimensionless factor termed $\tau_{0}$ (Rothbard, 1991). Sperm was UV irradiated as described in Lin and Dabrowski (1996a). Approximately 6000 eggs from each individual female were fertilized by $1 \mathrm{ml}$ of UV irradiated sperm and incubated at $12.3^{\circ} \mathrm{C}$. Separate portions of eggs were heat shocked at 1.0, $1.1,1.2,1.3,1.4$, and $1.5 \tau_{0}$ after fertilization for 3,6 , or $9 \mathrm{~min}$ in a $31.0 \pm 0.1^{\circ} \mathrm{C}$ water batch. For comparison, a batch of eggs was heat shocked at $20 \mathrm{~min}$ after fertilization for $6 \mathrm{~min}$ at $31.0^{\circ} \mathrm{C}$ for heterozygous gynogenesis. Three batches of eggs were incubated without heat-shock treatment to serve as a negative control of UV irradiation. Eggs were incubated in California-type hatching trays (Flex-a-lite Consolidated, Tacoma, WA). Survival to the eyed stage and hatching were recorded. Yield of diploid larvae was calculated as percentage of eyed embryos hatched out as normal diploid larvae (Lin and Dabrowski, 1996a).

\section{Statistical Analysis}

All parameters were expressed as mean and standard deviation. The statistical significance of the DNA content results was assessed by $F$-test for variances and Student's $t$-test for mean. Effects of initial time of treatment and duration of heat shock on the survival and percentage of diploid larvae were performed using two-way ANOVA. Comparison of the 
percentage of diploid larvae between various heat-shock groups and UV negative control groups was done using Student's $t$-test for mean.

\section{RESULTS}

\section{Effects of Incubation Media on the Egg Fertility}

Eggs maintained their fertility after incubation for $10 \mathrm{~min}$ in several media, including saline, Ringer's solution, and Ringer's solution supplemented with BSA in the range similar to muskellunge ovarian fluid (Fig. 1). However, sucrose solution and carp artificial fluid caused severe loss of egg fertility. The chemical compo sition of the ovarian fluid $(n=6)$ revealed that the concentrations for the major ions were as follows: sodium $(124.09 \pm 15.13 \mathrm{mM})$, potassium $(4.02 \pm 0.51 \mathrm{mM})$, phosphate $(2.64 \pm 1.06 \mathrm{mM})$, magnesium $(0.26 \pm 0.1 \mathrm{mM})$, and calcium $(1.83$ $\pm 0.40 \mathrm{mM})$.

\section{Effects of UV Irradiation on Embryonic Development}

Irradiation of eggs for more than $2 \mathrm{~min}\left(330 \mathrm{~J} / \mathrm{m}^{2}\right)$ reduced the egg fertility, as indicated by survival to the eyed-embryo stage, whereas irradiation for less than 1 min did not alter the egg fertility (Fig. 2). Most of the embryos hatched, both normal and abnormal, in all the groups except the group irradiated for $12 \mathrm{~min}\left(1980 \mathrm{~J} / \mathrm{m}^{2}\right)$. The percentage of abnormal larvae increased with the increasing time of UV irradiation. UV irradiation for more than $4 \mathrm{~min}$ led to $100 \%$ abnormal embryonic development. The morphology of the abnormal larvae, except those of the 12- min group, resembled that of haploid gynogenetic muskellunge (Lin and Dabrowski, 1996a). Most of the embryos from the 12-min group developed as a highly deformed form (Fig. 3). However, some of these embryos (cell mass) could survive up to 2 weeks after fertilization, at which time the control fish hatched.

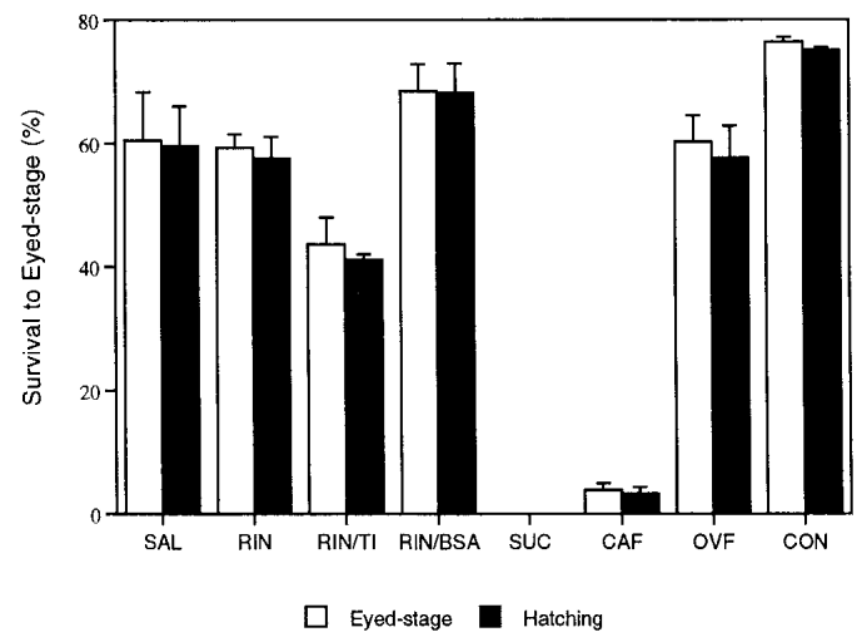

Fig. 1. Effects of egg incubation media on egg fertility. The abbreviations were described in the text.

\section{DNA Content Measured by Flow Cytometry}

Flow cytometry measurement of DNA content indicated that abnormal larvae from the 4to 12-min groups were all haploids, whereas those from the 0.5 and 1-min groups were diploids (Table 1). Abnormal larvae from the 2-min group were haploids, diploids, or haploid/diploid mosaics (Fig. 4). The DNA content of abnormal "diploid" larvae from the 1- to 2-min group 
was significantly lower than that of control fish and abnormal larvae from the 0.5-min group $(P$ $<0.01)$. The CV of the main fluorescent peak of the "diploid" abnormal larvae from the 0.5and 2-min groups was significantly higher than that of control groups. There were no significant differences in DNA content and CV of the main fluorescent peak among abnormal larvae from the 4- and 12-min groups. However, abnormal "haploid" larvae from the 2-min group had a significantly lower DNA content and higher CV of the main fluorescent peak than those of the 4and 12-min groups.

\section{Chromosomes and NORs Preparations}

Chromosome preparation of abnormal larvae from the 4-min group revealed haploids with a complete set of 25 chromosomes, while all control fish examined were diploids with 50 chromosomes (Fig. 5A,C). Chromosome fragments, probably of maternal source, were noticed in some of the cells (see Fig. 5B). Silver staining for NORs indicated only one nucleolus for the abnormal larvae.

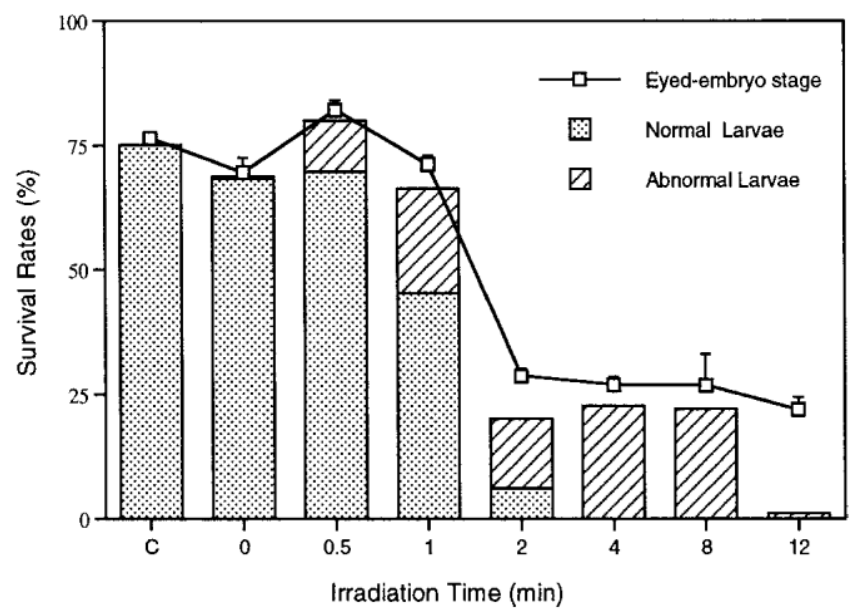

Fig. 2. Survival rates of eggs after being exposed to UV irradiation. Eggs were irradiated at an intensity of $275 \mathrm{~mW} / \mathrm{cm}^{2}$ for various durations in muskellunge ovarian fluid. $\mathrm{C}=$ control, fertilization of fresh eggs and sperm as gametes quality control. Deformed embryos (cell mass) survived to 7 days after fertilization and were used to calculate the survival to the eyed stage.

\section{Induction of Homozygous Gynogenesis by Heat Shock}

The dimensionless factor $\tau_{0}$ of muskellunge was determined to be $127 \mathrm{~min}$ at $12.3^{\circ} \mathrm{C}$. Survival to the eyed stage in the control groups for gamete quality was $80.2 \pm 6.4 \%$, which was slightly above the average fertilization success achieved in our laboratory. This indicated that the storage did not affect the quality of gametes. Survival to the eyed stage was expressed as relative survival in comparison with the gamete quality control group. Survival to the eyed stage was significantly $(P<0.001)$ affected by both initial time of heat shock and duration of treatment (Fig. 6). A reason able survival, in comparison with the negative groups, was obtained in all the groups exposed to heat shock for $3 \mathrm{~min}$. Heat shock for 6 and $9 \mathrm{~min}$ had more severe influence on the survival of eggs if it was applied at 1.3 to $1.5 \tau_{0}$ after fertilization. Diploid larvae were obtained in all heat-shock groups. There were significant differences $(P<0.001)$ among the various initial times of treatment but no significant differences among the durations of heat shock. Diploids also were presented in the negative control group. However, most of the heat 
shocked groups, except 1.2 and $1.5 \tau_{0}$, showed a significantly $(P<0.01)$ higher yield of diploid larvae than the negative control group. Ploidy of the larvae was verified using a flow cytometry method. The heat-shock treatment at $31^{\circ} \mathrm{C}$ for 9 min starting at $1.4 \tau_{0}$ after fertilization produced the highest percentage of diploids at hatching.

\section{DISCUSSION}
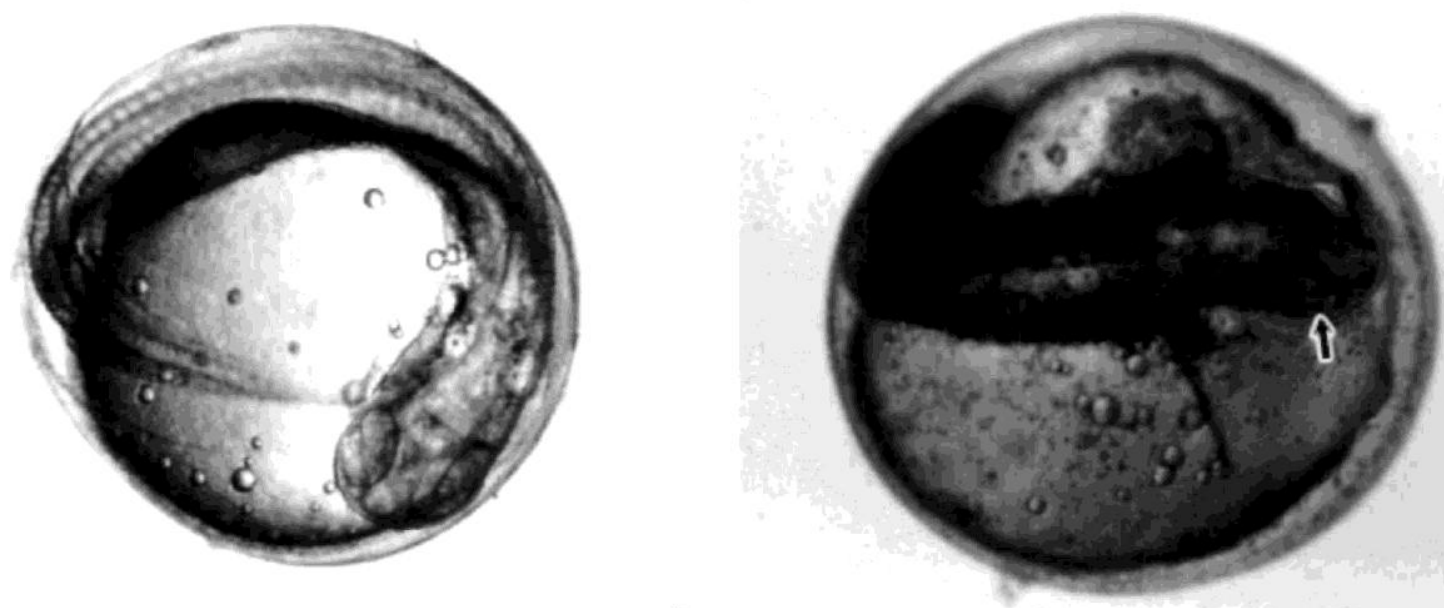

A
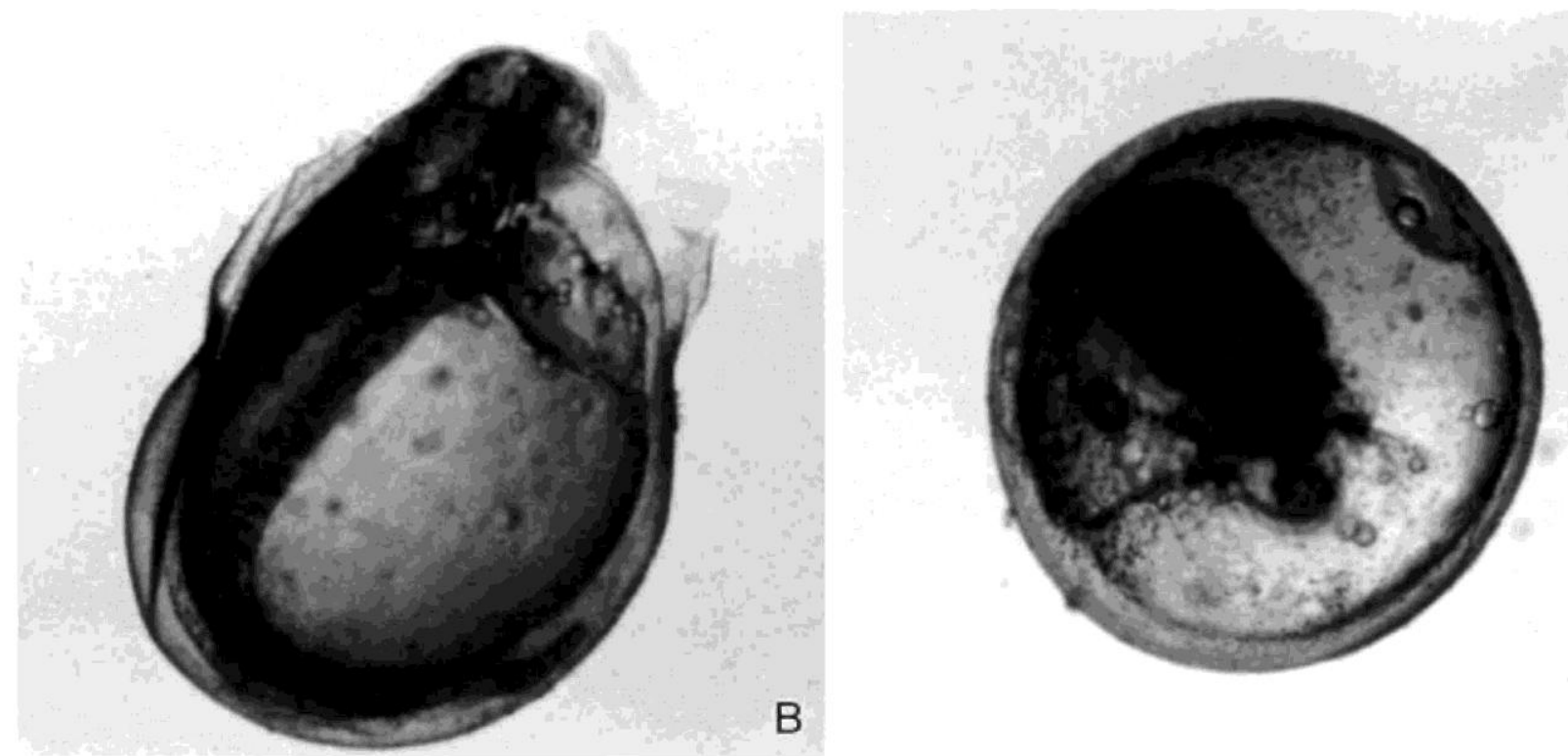

B

Fig. 3. Morphology of haploid embryos and various degrees of deformed embryos. A: Diploid control embryo (×18.5) (Lin and Dabrowski, 1996a). B: Haploid embryo in the process of hatching. C: Highly deformed embryo with distinguishable eyes (arrow). D: Cell mass without distinguishable organs. The magnification was $21 \times$ for B, C, and D. Pictures were taken 11 days after fertilization.

Fertility of eggs of various fish species can be retained for a few hours in artificial media (see review by Stoss, 1983). Our previous study shows that muskellunge eggs can be stored at $12^{\circ} \mathrm{C}$ for up to $8 \mathrm{hr}$ without severe loss of viability (Lin and Dabrowski, 1996a). In the present 
experiment, we found that simple salt solutions such as a saline and fish Ringer's solution could retain the fertility of muskellunge for $10 \mathrm{~min}$, a period long enough for UV irradiation. A similar result was reported for rainbow trout eggs (Erdahl et al., 1987). The reason for the reduced viability after incubation in $0.3 \mathrm{M}$ sucrose and carp artificial fluid is unknown. The concentrations of sodium and calcium in ovarian fluid are similar to those of seminal plasma, while potassium and magnesium are several folds lower in ovarian fluid (Lin et al., 1996). Calcium at $3 \mathrm{mM}$ and higher was found to have an inhibitory effect on sperm motility in muskellunge (Lin and Dabrowski, 1996b). This could be a reason for the reduced egg fertility in the carp artificial fluid, which contained $2.7 \mathrm{mM} \mathrm{CaCl}_{2}$.

Our results indicated that UV irradiation was inactivating the nuclear DNA in muskellunge eggs. The yield of viable denucleated eggs was $22.5 \pm 2.8 \%$ under of optimal UV irradiation doses $\left(660-1320 \mathrm{~J} / \mathrm{m}^{2}\right)$. The yield is comparable with that of $22.9 \%$ in Nile tilapia (Myers et al., 1995) and $22 \%$ in loach (Arai et al., 1995). The optimal UV dose also was similar to the dosages suggested for Nile tilapia (450-900 J/m²) (Myers et al., 1995). In common carp, an optimal dose of $2500 \mathrm{~J} / \mathrm{m}^{2}$ produced $53.9 \%$ haploids at hatching as well as a few biparental diploids (Bongers et al., 1994). The UV dose used in loach eggs was $7500 \mathrm{erg} / \mathrm{mm}^{2}$ over a duration of 1 min (Arai et al., 1995). Variable sensitivity to UV irradiation from species to species can be explained by differences in chorion structure, egg size and shape, and the relative position of the female pronucleus (Myers et al., 1995).

TABLE 1. Relative DNA Content of Abnormal Muskellunge Larvae Measured by Flow Cytometry Method after UV Irradiation of Eggs

\begin{tabular}{|c|c|c|c|c|c|c|}
\hline \multirow{2}{*}{$\begin{array}{l}\text { UV irradiation } \\
\text { time (min) }\end{array}$} & \multirow[b]{2}{*}{ Relative DNA content $^{\mathrm{a}}$} & \multirow{2}{*}{$\begin{array}{l}\mathrm{CV} \text { of muskellunge } \\
\text { fluorescent peak }\end{array}$} & \multicolumn{3}{|c|}{ Ploidy } & \multirow[b]{2}{*}{ Total number } \\
\hline & & & $1 n$ & $2 n$ & $1 n / 2 n^{b}$ & \\
\hline $0^{c}$ & $0.480 \pm 0.006$ & $4.64 \pm 0.34$ & & 9 & & 9 \\
\hline 0.5 & $0.473 \pm 0.008$ & $5.07 \pm 0.84$ & & 10 & & 10 \\
\hline 1 & $0.457 \pm 0.012^{\mathrm{e}}$ & $5.97 \pm 1.46$ & & 10 & & 10 \\
\hline \multirow[t]{2}{*}{2} & $0.449 \pm 0.137^{\mathrm{e}}$ & $6.66 \pm 1.25^{\mathrm{f}}$ & & 6 & 1 & $12^{\mathrm{h}}$ \\
\hline & $0.197 \pm 0.009$ & $21.68 \pm 2.77 \mathrm{~g}$ & 4 & & & \\
\hline 4 & $0.234 \pm 0.012$ & $13.37 \pm 2.79$ & 11 & & & 11 \\
\hline 8 & $0.230 \pm 0.009$ & $13.84 \pm 2.25$ & 11 & & & 11 \\
\hline $12^{\mathrm{d}}$ & $0.239 \pm 0.012$ & $14.43 \pm 2.76$ & 9 & & & 9 \\
\hline
\end{tabular}

aExpressed as percentage of DNA fluorescence to the rainbow trout red blood cells (internal standard), mean \pm SD.

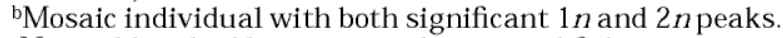

cNormal hatched larvae served as control fish.

dAbnormal embryos (cell mass).

eSignificantly lower than groups 0 and $0.5 \min (P<0.01)$.

fSignificantly higher than those of groups 0 and $0.5 \mathrm{~min}(P<0.05)$

gSignificantly higher than those of groups $4-12 \mathrm{~min}(P<0.01)$.

hOne of 12 larvae showed no DNA peak. The CV of the TRBC standard peak was $2.80 \pm 0.34$ $(n=72)$.

Radiation can induce structural chromosome aberrations and thus produce an increased dispersion of cellular DNA in proliferating cell populations (George et al., 1991). An unequal distribution of DNA in the daughter cells would lead to increased $C V$ of $G_{0} / G_{1}$ peak in the histogram of DNA content measured by flow cytometry. Radiation-induced chromosome damage has been suggested as the cause of an increase in intercellular variations in DNA content (Lamb et al., 1991; George et al., 1991). In the present study, UV irradiation at $82.5 \mathrm{~J} / \mathrm{m}^{2}$ produced some abnormal muskellunge larvae with a "haploid syndrome." We noted that nuclear DNA content of these abnormal larvae using flow cytometry showed no difference from that of the control group but had an increased coefficient of variation of the $G_{0} / G_{1}$ peak. This indicated 
that UV irradiation at this dosage might cause some mutations in the genomes of the fish and result in abnormal embryonic development similar to that in haploids. Nuclear DNA content of the abnormal larvae that resulted from irradiation at $165-330 \mathrm{~J} / \mathrm{m}^{2}$ was close to that of diploids but significantly lower. A wider distribution in DNA content than that of control fish suggests a partial chromosomal fragmentation occurring in these fish. Inactivation of maternal genomes and partial fragmentation of chromosomes did not prevent them from being involved in mitotic divisions. Some of the abnormal larvae in the $330 \mathrm{~J} / \mathrm{m}^{2}$ groups had the DNA content of haploids. This indicated that maternal chromosomes did not participate in the mitotic division. Nuclear DNA content of haploids from groups of more than $660 \mathrm{~J} / \mathrm{m}^{2}$ irradiation did not differ from half the DNA content of control fish. However, chromosomal fragments were noticed in some cells of abnormal larvae in the 4-min group (see Fig. 5C).

The effects of UV irradiation on eggs are lacking in consistency among various authors. Myers et al. (1995) reported that mtDNA, analyzed with ultraviolet endonuclease and autoradiographs, was not affected by doses of UV irradiation high enough to denucleate the eggs. This suggested that UV irradiation has relatively little impact on the eggs beyond nuclear inactivation. However, Bongers et al. (1995) reported that yields of androgenetic diploids and the frequency of normal and abnormal fry at 10 weeks of age mainly depended on egg donors. They suggest that UV irradiation also might damage the maternal RNA in eggs, which is essential for the development up to the blastula stage, and thus affect differentiation processes of embryonic development by altering cell fates and lineages. We found that eggs developed only as cell mass, with the nuclear DNA content of haploids, after being irradiated at a dose of $1980 \mathrm{~J} / \mathrm{m}^{2}$ in muskellunge. This suggests that UV irradiation at such a dose severely damaged the eggs and impaired their embryonic development.

Color and allozyme markers are widely used as indicators of successful induction of androgenesis as well as gynogenesis. Our results suggest that inactivated and even partially fragmented maternal chromosomes might be involved in the cell division. Similar results have been obtained in tilapia, Oreochromis aureus, in which paternal transmission was found in gynogenetic fish using DNA fingerprinting (Carter et al., 1991). In the present study on muskellunge, DNA fragments, probably of maternal chromosomes residues, were found in some of the specimens. A similar evidence has been obtained in loach (Arai et al., 1992). However, an appropriate dose of UV irradiation can be identified as producing no residual DNA fragments, especially in the induction of gynogenesis. This would be an advantage over gamma irradiation (Chourrout, 1984). Chromosome fragments usually were generated by ionizing irradiation and might interfere with the embryonic development (Chourrout and Quillet, 1982; Parsons and Thorgaard, 1984). Disney et al. (1988) has demonstrated the maintenance of foreign gene expression and independent chromosome fragments in adult transgenic albino rainbow trout, generated by the chromosome-mediated gene transfer method, and the inhabitability of these chromosome fragments to their backcrossed offspring. Thus color and allozyme markers might not be sufficient to prove a complete androgenesis or gynogenesis. The interference from the maternal DNA fragments, which might not be detected by color and allozyme markers, could be another reason for the poor visability and performance of androgenetic fish. 


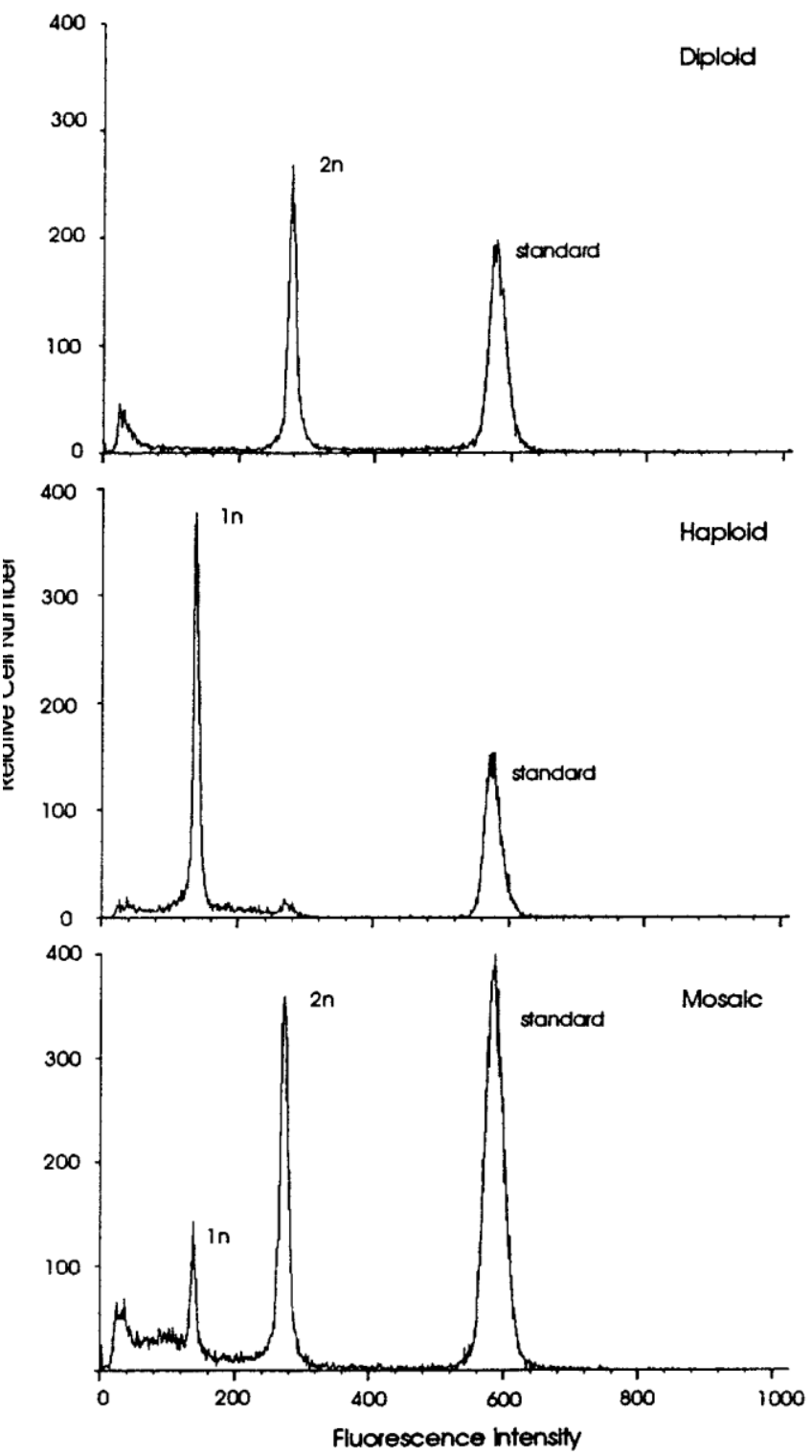

Fig.4

Fig.5

Fig. 4. Representative distribution of fluorescence of cells prepared from abnormal larvae, which morphologically resemble the haploids, measured by a flow cytometer. Rainbow trout red blood cells were used as an internal standard. Each panel was an output of an individual fish. 

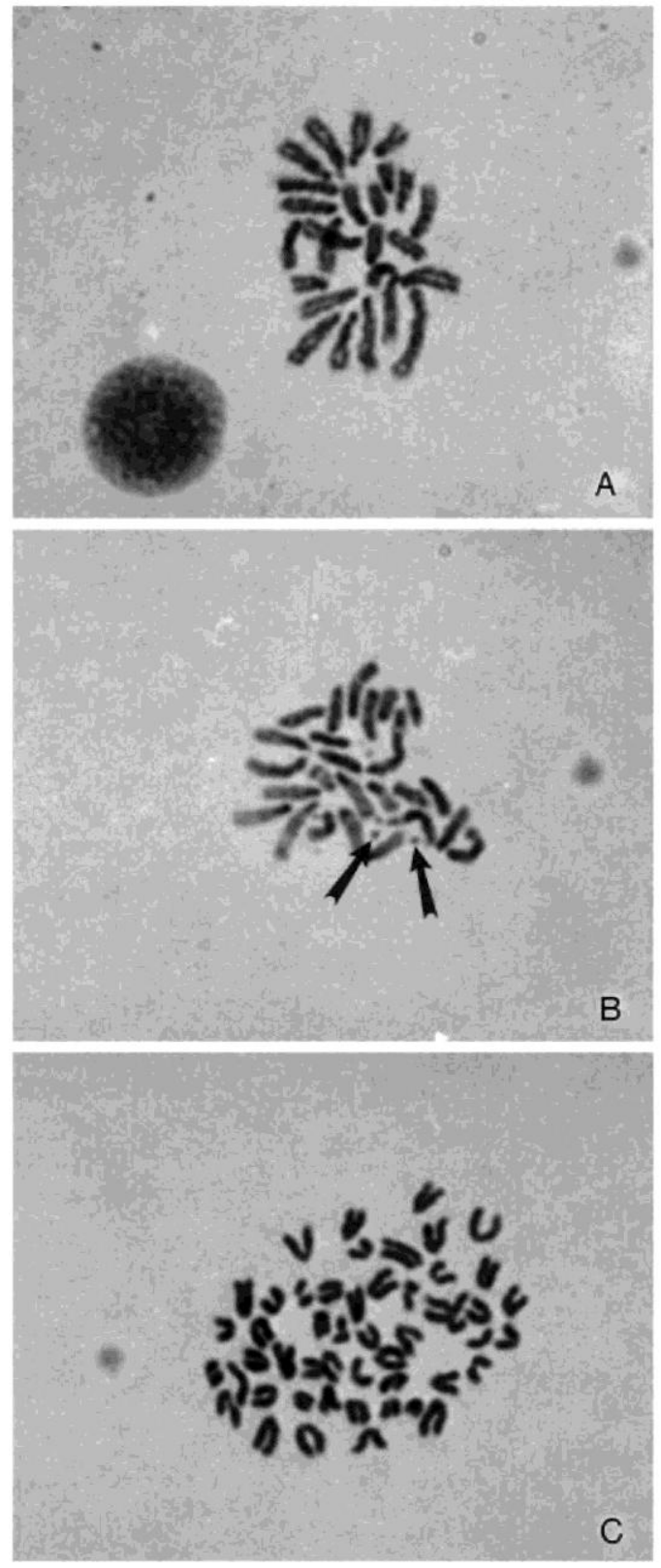

Fig. 5. A: Chromosomes of muskellunge prepared from abnormal larvae (UV irradiation for $4 \mathrm{~min}$ ) were haploids with 25 chromosomes. B: DNA fragments, as indicated by arrows, were observed in some of the specimens. C: Control fish were diploid with 50 chromosomes. $(\times 1500$. 


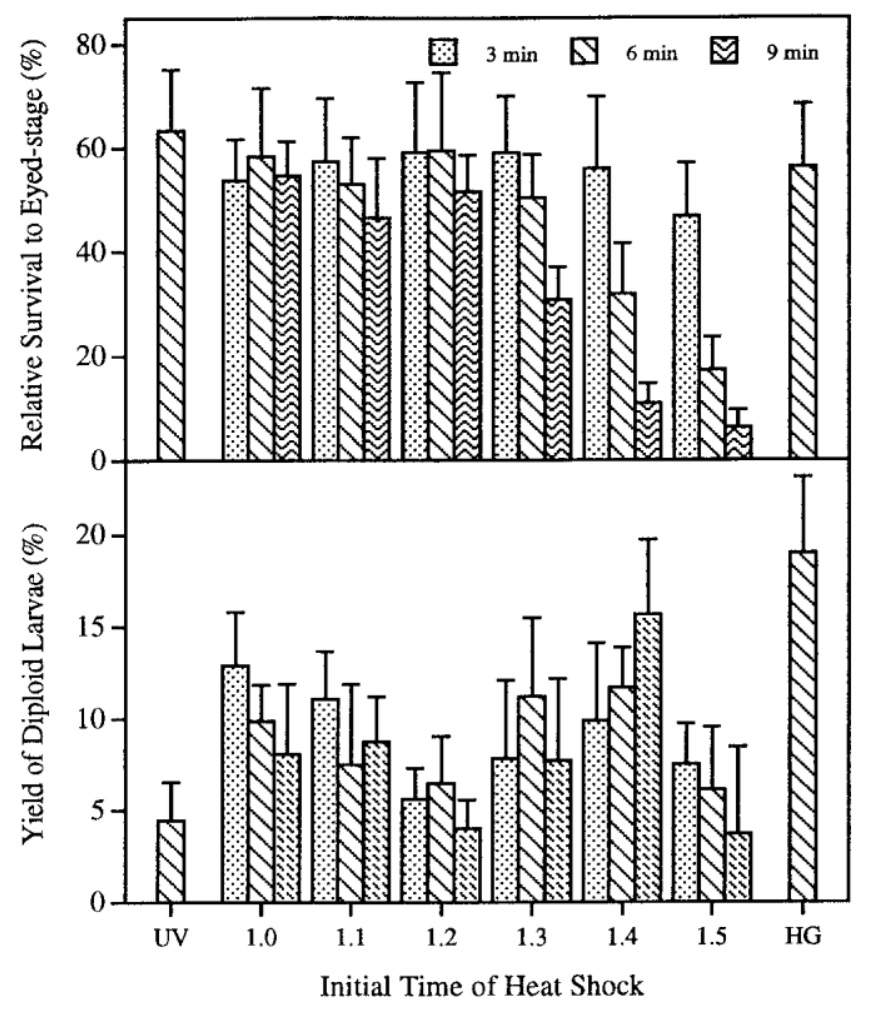

Fig. 6. Effect of heat-shock treatments on the survival to the eyed stage and yield of gynogens. Control for gamete quality had an $80.2 \pm 6.4 \%$ survival to the eyed stage. Relative survival was expressed as percentage as comparison with the gamete quality control group. Heat shock was done in a water bath at $31.0 \pm 0.1^{\circ} \mathrm{C}$ for 3,6 , or 9 min starting at various times after fertilization. The dimensionless factor ${ }_{\mathrm{T}}$ for muskellunge was determined to be $127 \mathrm{~min}$ at a water temperature of $12.3^{\circ} \mathrm{C}$. $\mathrm{HG}=$ heterozygous gynogenesis group with initial time of heat shock at $20 \mathrm{~min}$ after fertilization. UV $=$ eggs were fertilized with UV = irradiated sperm but not exposed to heat shock (negative control).

In the experiment of homozygous gynogenesis, survival to the eyed stage in the negative control and heterozygous gynogenesis groups was similar to our previous results (Lin and Dabrowski, 1996a). We observed a small percentage of dipoloid larvae. There were two possible explanations for this phenomenon. First, some sperm might not have been inactivated by UV and fertilized the eggs. Second, spontaneous diploidization may occur in those eggs, as demonstrated in ornamental koi $\times$ carp, Cyprinus carpio, by Cherfas et al. (1991). We have observed in our laboratory spontaneous gynogenesis in muskellunge using UV-irradiated yellow perch sperm (unpublished data). Heat-shock treatments significantly increased the percentage of diploid larvae $n$ most of the groups. This indicated that the heat shock should have successfully induced diploidization at least in some of the eggs. We found that a severe heat-shock treatment $\left(31^{\circ} \mathrm{C}\right.$ for $\left.9 \mathrm{~min}\right)$ starting at $1.4 \tau_{0}$ after fertilization produced the highest percentage of diploid larvae, approximately four times higher than the negative control. The best initial time of treatment was in agreement with the one (1.2 to $\left.1.4 \tau_{0}\right)$ reported for the Japanese ornamental carp (Rothbard, 1991).

In summary, we found the optimal doses of UV irradiation $\left(660-1320 \mathrm{~J} / \mathrm{m}^{2}\right)$ to achieve complete de nucleation of muskellunge eggs at a haploid larvae hatching rate of $22.5 \pm 2.8 \%$. Our flow cytometry results indicated that a low dose of UV irradiation might cause gene 
mutations, alteration of chromosomal conformation, and fragmentation but did not prevent maternal DNA from participating in mitotic division. Our results also suggested that classic color and allozyme markers might not be sufficient to prove a complete androgenesis. Our observations on the effects of UV irradiation on the denucleation of eggs revealed that the induction of haploids in the developing embryos is a more complex phenomenon than was originally believed. We found that heat-shock treatment at $31{ }^{\circ} \mathrm{C}$ for 9 min starting at $1.4 \tau_{0}$ after fertilization produced the highest percentage of diploids at hatching.

\section{ACKNOWLEDGMENTS}

We appreciate helpful cooperation in sampling gametes from Richard Day and Frank Kapler, the Ohio Division of Wildlife. Thanks are also due to Dan Brewer of the Minor E. Clark Fish Hatchery, Kentucky, for the provision of muskellunge gametes. Joseph O. Trask, Jr., of the Comprehensive Cancer Center offered technical help in operating the flow cytometer. This work was funded by the Federal Aid in Sport Fish Restoration Program (F-69P, Fish Management in Ohio) administered jointly by the United States Fish and Wildlife Service and the Ohio Division of Wildlife. Salaries were partly provided by the state and federal funds appropriated to the Ohio Agriculture Research and Development Center and the Piketon Research and Extension Center. Manuscript No. $00 / 97$.

\section{REFERENCES}

Allen SK Jr (1983): Flow cytometry: Assaying experimental polyploidy in fish and shellfish. Aquaculture 33:317328.

Arai K, Onozato H, Yamazaki F (1979): Artificial androgenesis induced with gamma irradiation in masu salmon, Oncorhynchus masou. Bull Fac Fish Hokkaido Univ 30:181-186.

Arai K, Masaoka T, Suzuki R (1992): Optimum conditions of UV ray irradiation for genetic inactivation of loach eggs. Nippon Suisan Gakkaishi 58:1197-1201.

Arai K, Ikeno M, Suzuki R (1995): Production of androgenetic diploid loach Misgurnus anguillicaudatus using spermatozoa from natural tetraploids. Aquaculture 137:131-138.

Benfey TJ, Solar II, de Jong G, Donaldson EM (1986): Flow-cytometric confirmation of aneuploidy in sperm from triploid rainbow trout. TransAm Fish Soc 115:838-840.

Bickham JW, Hanks BG, Smolen MJ, Lamb T, Gibbons JW (1988): Flow cytometric analysis of the effects of lowlevel radiation exposure on natural populations of silder turtles (Pseudemys scripta). Arch Environ Contam Toxicol 17:837-841.

Bongers ABJ, in't Veld EPC, Abo-Hashema K, Bremmer IM, Eding EH, Komen J, Richter CJJ (1994): Androgenesis in common carp (Cyprinus carpio L.) using UV irradiation in a synthetic ovarian fluid and heat shocks. Aquaculture 122:119-132.

Bongers ABJ, Boza Abarca J, Zandieh Doulabi B, Eding EH, Komen J, Richter CJJ (1995): Maternal influence on development of androgenetic clones of common carp, Cyprinus carpio L. Aquaculture 137:139-147.

Carter RE, Mair GC, Skibinski DOF, Parkin DT, Beardmore JA(1991): The application of DNA fingerprinting in the analysis of gynogenesis in tilapia. Aquaculture 95:41-52.

Cherfas NB, Rothbard S, Hulata G, Kozinsky O (1991): Spontaneous diploidization of maternal chromosome set in ornamental koi X carp Cyprinus carpioL. JAppl Ichthyol 7:72-77.

Chourrout D (1984): Pressure-induced retention of second polar body and suppression of first cleavage in rainbow trout: Production of all-triploids, all-tetraploids, and heterozygous and homozygous diploid gynogenetics. Aquaculture 36:111-126.

Chourrout D, Quillet E (1982): Induced gynogenesis in rainbow trout: Sex and survival of progenies. Production of all-triploid populations. Theor Appl Genet 63:201-205.

Dallas CE, Evan DL (1990): Flow cytometry in toxicity analysis. Nature 345:557-558.

Deaven LL (1982): Application of flow cytometry to cytogenetic testing of environmental mutagens. In TC Hsu (ed): "Cytogenetic Assays of Environmental Mutagens." Allanheld, Totwa, NJ: Osmun Publishers, pp 325-351.

Disney JE, Johnson KR, Banks DK, Thorgaard GH (1988): Maintenance of foreign gene expression and independent chromosome fragments in adult transgenic rainbow trout and their offspring. J Exp Zool 248:335-344.

Erdahl AW, Cloud JG, Graham EF (1987): Fertility of rainbow trout (Salmo gairdneri) gametes: gamete viability in 
artificial media. Aquaculture 60:323-332.

George LS, Dallas CE, Brisbin IL Jr, Evan DL (1991): Flow cytometric DNA analysis of ducks accumulating ${ }^{137}$ Cs on a reactor reservoir. Ecotoxicol Environ Safe 21:337-347.

Hsu SY, Goetz FW (1993): Inhibition of chorion expansion and preservation of fertility in goldfish (Carassius auratus) eggs by protease inhibitors. Can J FishAquatSci 50:932-935.

Johnson OW, Utter FM, Rabinovitch PS (1987): Interspecies differences in salmonid cellular DNA identified by flow cytometry. Copeia 1987:1001-1009.

Lamb T, Bickham JW, Gibbons JW, Smolen MJ, McDowell S (1991): Genetic damage in a population of slider turtle (Trachemys scripta) inhabiting a radioactive reservoir. Arch Environ Contam Toxicol 20:138-142.

Lin F, Dabrowski K (1996a): Effects of sperm irradiation and heat shock on induction of gynogenesis in muskellunge (Esox masquinongy). Can J Fish Aquat Sci 53:2067-2075.

Lin F, Dabrowski K (1996b): Characteristics of muskellunge spermatozoa: II. Effects of ions and osmolality on sperm motility. Trans Am Fish Soc 125:195-202.

Lin F, Liu L, Dabrowski L (1996): Characteristics of muskellunge spermatozoa: I. Ultrastructure of spermatozoa and biochemical composition of semen. Trans Am Fish Soc 125:187-194.

May B, Henley KJ, Krueger CC, Gloss SP (1988): Androgenesis as a mechanism for chromosome set manipulation in brook trout (Salvelinus fontinalis). Aquaculture 75:57-70.

Myers JM, Penman DJ, Basavaraju Y, Powell SF, Baopraserkul P, Rana KJ, Bromage N, McAndrew BJ (1995): Induction of diploid androgenetic and mitotic gynogenetic Nile tilapia (Oreochromis niloticus L.). Theor Appl Genet 90:205-210.

Parsons JE, Thorgaard GH (1984): Induced androgenesis in rainbow trout. J Exp Zool 231:407-412.

Parsons JE, Thorgaard GH (1985): Production of androgenetic diploid rainbow trout. J Hered 76:177-181.

Purdom CE (1969): Radiation-induced gynogenesis and androgenesis in fish. Heredity 24:431-444.

Rothbard, S (1991): Induction of endomitotic gynogenesis in the Nishiki-goi, Japanese ornamental carp. Isr J Aquaculture 43:145- 155 .

Scheerer PD, Thorgaard GH, Allendorf FW, Knudsen KL (1986): Androgenetic rainbow trout produced from inbred and outbred sperm sources show similar survival. Aquaculture 57:289-298.

Stoss J (1983): Fish gamete preservation and spermatozoa physiology. In WS Hoar, DJ Randall, EM Donaldson (eds): “Fish Physiology," vol IXB. New York:Academic Press, pp 305-350.

Thorgaard GH, Scheerer PD, Hershberger WK, Myers JM (1990): Androgenetic rainbow trout produced using sperm from tetraploid males show improved survival. Aquaculture 85:215-221.

Thorgaard GH, Scheerer PD, Parson LE (1985): Residual paternal inheritance in gynogenetic rainbow trout: Implications for gene transfer. Theor Appl Genet 71:119-121.

Tiersch TR, Chandler RW, Wachtel SS, Elias S (1989): Reference standards for flow cytometry and application in comparative studies of nuclear DNA content. Cytometry 10:706-710. 